\title{
ANNOUNCEMENTS
}

\author{
Special Issue of Physiological Psychology \\ The Role of the Hippocampus in Learning and Memory
}

The June 1980 issue of Physiological Psychology will be a special issue containing the papers from a symposium on The Role of the Hippocampus in Learning and Memory. Contributors to the issue include: T. W. Berger, P. L. Ellen, R. Hirsh, R. L. Isaacson, L. W. Jarrard, R. P. Kesner, J. W. Moore, L. W. Nadel, J. O'Keefe, D. Olton, W. R. Salafia, P. R. Solomon, R. F. Thompson, and G. Winocur. The conference was held at Williamstown, Massachusetts, on June 25, 26, and 27, 1979.

\section{Symposium on Aging and Human Visual Function Washington, D.C. March 31 - April 1, 1980}

The objective of this conference, sponsored by the National Academy of SciencesNational Research Council Committee on Vision, is to draw together what is known and point out how much is not known about basic changes in human vision that occur with age. It will provide vision scientists an opportunity to become better acquainted with gerontological issues and will delineate needs and problems for doing good research in this field. Topics discussed will include: General considerations (demographic aspects, methodological concerns, concepts of aging, disease vs. normal change); Ocular changes; Changes in visual functions; Perceptual changes; Neurological and circulatory aspects; and Human factors (quality of life, environmental design, compensatory approaches).

For further information, please contact:

Key Dismukes

Study Director

Committee on Vision

NAS-NRC

2101 Constitution Avenue, N.W.

Washington, D.C. 20418

(202) 389-6505 